\title{
Investigation of Microstructure, Mechanical \& Electrochemical Behaviors of Martensitic Stainless Steel (MSS) and Alloyed White Cast Iron (WCI) Rolls Fabricated by a Centrifugal Casting
}

\author{
Mehmet OKTAY'®i), Efe TAŞCI ${ }^{1}$ Burak KÜÇÜKELYAS ${ }^{*}$ BD Deniz UZUNSOY ${ }^{3}$ \\ ${ }^{1}$ ENTIL End. Yat. ve Tic. A.Ş. R\&D Center, 26110, Eskişehir, Turkey \\ 2 Bursa Technical University, Metallurgical and Materials Engineering Department, 16310, Bursa, Turkey
}

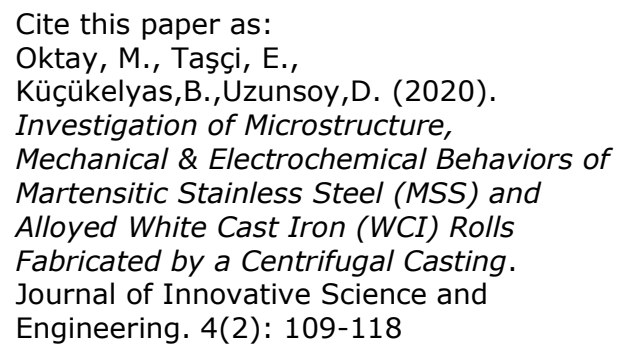

*Corresponding author: Burak Küçükelyas E-mail: burak.kucukelyas@btu.edu.tr Tel: +90 (224) 3003509

Received Date: $12 / 06 / 2020$

Accepted Date: 16/09/2020

(C) Copyright 2020 by

Bursa Technical University. Available online at http://jise.btu.edu.tr/

The works published in Journal of Innovative Science and Engineering (JISE) are licensed under a Creative Commons Attribution-NonCommercial 4.0 International License.

\begin{abstract}
The present study focuses on the production of two kinds of composite rolls by the horizontal centrifugal casting process and the investigation of the chemical composition, microstructure, mechanical \& electrochemical behaviors of the products. Alloyed white cast iron (WCI) and martensitic stainless steel (MSS) were successfully produced with this method. The chemical compositions of the produced materials were examined by XRay Fluorescence Analysis (XRF). The microstructural properties were examined using an optical microscope (OM). These produced rolls are developed for grinding purposes. The rolls used in the grinding process must also have higher hardness values, so Vickers hardness measurements are performed on the WCI and MSS alloys. Moreover, produced rolls intended to work in corrosive working environment as well. Due to these requirements, the corrosion resistance plays important role for these rolls. Corrosion behavior of casted samples were investigated via potentiodynamic polarization measurements.
\end{abstract}

Keywords: Centrifugal Casting, White Cast Iron, Martensitic Stainless Steel, Tafel Extrapolation, Corrosion Rate. 


\section{Introduction}

Centrifugal casting is an extensively used method in producing metal rolls and has the advantages of less pollution, low energy consumption, high efficiency and simplicity. Centrifugal casting process has no limitation for casting metal materials and it gives opportunity to cast any material which you can cast with static casting. Centrifugal casting can be best defined as "isotropic" owing to having equal properties in all directions. Other production methods (forging, static casting) cannot provide equal properties in all directions. Centrifugal casting process is a best choice for producing hollow cylinders with specific advantages. First of all, that method has high casting yield, and there is no gating system or risers. During casting, a solidification directed from the outer surface of the mold towards the inner surface takes place. At the same time, the metal is fed from outside to inside as a result of high pressure caused by centrifugal effect. In addition, due to the centrifugal force, high density particles go to the outer surface while undesirable impurities like dross, oxides etc. move towards the inner surface and this inner surface could be easily machined away [1].

True centrifugal casting technique, also called to as just centrifugal casting, is characterized by an outer cylindrical mold without cores. The system can be horizontal, vertical or inclined. The essential feature of centrifugal casting is the pouring of molten metal into a permanent mold, which is rotating at 300-3000 rpm. Centrifugal casting is generally used in the production of cylindrical hollow parts because it eliminates the need for a core. In addition, the fact that it has directional solidification from the outside to the inside eliminates the drawback, which is the biggest defect in conventional castings [2].

Another advantage of horizontal centrifugal casting process is the convenient pouring of bimetallic materials. It is applied by pouring one alloy after another alloy. There are two main reasons for the production of bimetallic materials. The first is to supplement the desired special material with another cheaper material. The second is to provide a combination of features that cannot be achieved by other methods. There is no general rule as to which bimetallic materials should be used [3]. Fig. 1 shows the schematic view of horizontal centrifugal casting process.

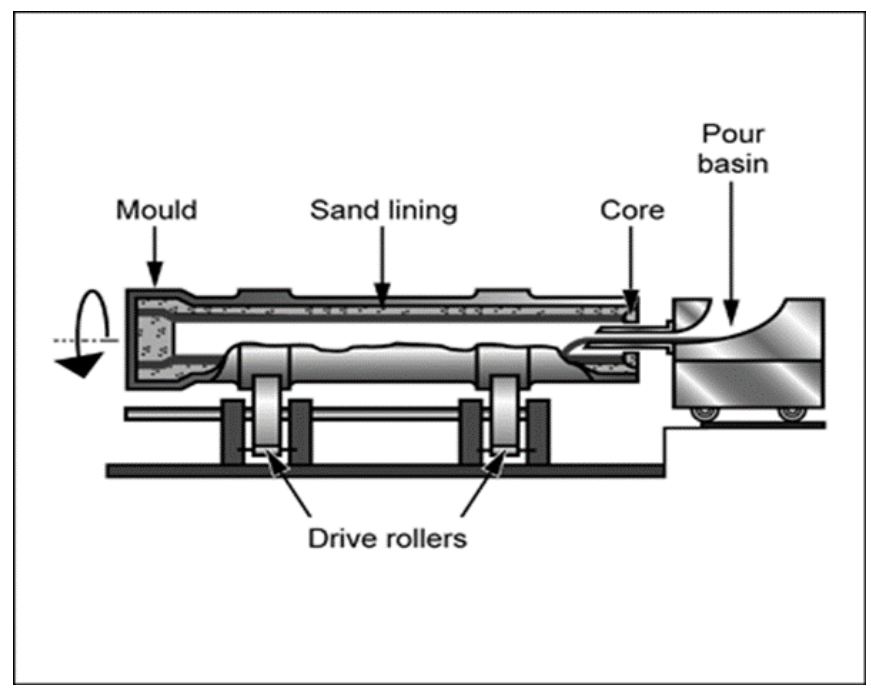

Figure 1. Schematic view of centrifugal casting process [4] 
Bimetallic materials, which are bonded with different metals or alloys in layered structure are very promising because they combine the best properties of the two materials. In examined roll outer shell material MSS and WCI has good corrosion resistance and good wear resistance while core material has good toughness and good machinability [5, 6]. The development of materials is important for equipment operating under harsh conditions. The improvement in materials should provide a higher quality, longer service life and a cheaper production. In order to adapt to the harsh working conditions encountered in the industry, new alloys must have better mechanical properties and corrosion resistance [7].

If the carbon in the iron structure cannot form graphite during solidification, white cast iron is formed. White cast irons are so called because of the white fraction surface. This appearance is formed due to the carbides in the structure. The carbon in the structure of cast iron is seen only in the form of carbide in white cast irons. The presence of carbides makes white cast irons extremely hard and abrasion resistant but very brittle. Alloy elements in white cast iron are often used to improve wear properties [8].

The studies in the related literature show that high chromium content alloys exhibit good erosion-abrasive and erosioncorrosive behaviours. White cast irons with high chromium content are recently used in some potential applications such as mechanical parts exposed to high wearing. They are also used in fields where high corrosion resistance is needed [9]. Martensitic stainless steels are commonly used thanks to their superb mechanical properties and better corrosion properties. However, the requirements of better properties in distinctive applications has led to great research purposed at enhancing the performance of these steels [10]

Martensitic stainless steels combining high strength, toughness and corrosion resistance. In the martensitic structure carbon and chromium content are balanced. Small amount of nickel can be added into the composition to improve corrosion resistance and toughness [11].

In this study, WCI/ductile iron double layer and MSS/ductile iron double layer are casted using a centrifugal casting process. The chemical compositions of samples are examined with X-ray Fluorescence Spectroscopy (XRF). The microstructures of samples are obtained via an optical microscope. Hardness measurements are performed to investigate the mechanical properties of casted steels. Polarization curves of MSS and WCI are obtained and corrosion rates of samples are investigated by Tafel extrapolation method in a $3.5 \% \mathrm{NaCl}$ solution.

\section{Material and Methods}

\subsection{Fabrication and Preparation of Samples}

MSS/ductile iron and WCI/ductile iron double layer bimetallic rolls were prepared by centrifugal composite casting. MSS roll and WCI roll were poured at same casting conditions. Casting temperatures for WCI outer shell and MSS outer shell were $1470^{\circ} \mathrm{C}$ and $1570^{\circ} \mathrm{C}$, respectively. The casting of inner core from ductile iron was carried out at $1380^{\circ} \mathrm{C}$. The final 
casting products were about $1750 \mathrm{~kg}$ per product. After the cooling period, obtained rolls were reduced to $\varnothing 420 \mathrm{~mm}$ diameter and $1320 \mathrm{~mm}$ length by turning operation in Entil-Eskişehir foundry. The final form of the product is shown at the Fig. 2a. The outer shell material diffusion zone between shell and core material is shown at the Fig. 2b. The corrosion test specimens were taken from the outer to inner of MSS and WCI, and dimensions of samples were $1 \mathrm{~mm} \times 25 \mathrm{~mm} \times$ $25 \mathrm{~mm}$.

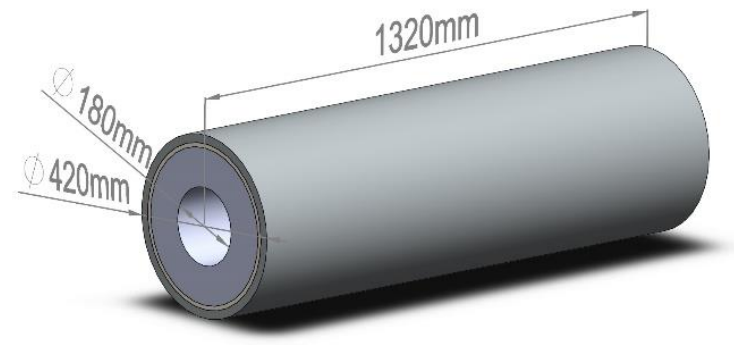

(a)

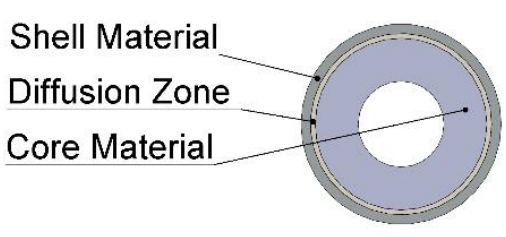

(b)

Figure 2. a) Final form and dimensions of the roll b) Shell material, diffusion zone, core material

\subsection{Methods Used for Determination of Chemical Composition, Microstructure and Mechanical \& Electrochemical Behaviors of Samples}

Wavelength Dispersive X-ray Fluorescence Spectroscopy (WDXRF) measurements are preformed to investigate the chemical compositions of samples by Rigaku Supermini200 WDXRF Spectrometer.

The alloyed white cast iron (WCI) samples are etched with \%2 nital solution while, mixture of glycerine, $\mathrm{HNO}_{3}$ and $\mathrm{HCl}$, at volume ratios of 2, 1 and 3 is used to etch martensitic stainless steel (MSS) samples. The microstructures of the samples are investigated using a Nikon-Eclipse LV150N optical microscope (OM).

Hardness values of the samples are examined using Qness Q10 Hardness Tester under a load of $5 \mathrm{~kg}$ and results represent the arithmetic mean of seven separate measurements.

Corrosion test is performed via a conventional three electrode cell setup and a CH Instruments ${ }^{\mathrm{TM}}$ CHI608 electrochemical workstation. The electrolyte solution is prepared using a high purity $\mathrm{NaCl}$ (Merck >\%99.9 Purity) salts. The samples are prepared using 100, 250, 500, and 800 grit size SiC papers, respectively. $\mathrm{Ag} / \mathrm{AgCl}$, platinum and the samples are used as the reference, counter, and the working electrodes, respectively. All measurements are taken in a $3.5 \mathrm{wt} . \% \mathrm{of} \mathrm{NaCl}$ solution. The polarization curves are recorded at a scan rate of $2 \mathrm{mV} / \mathrm{s}$ and at potential ranges of -250 to $+250 \mathrm{mV}$ with respect to open circuit potential (OCP) of samples. 


\section{Result and Discussions}

\subsection{Wavelength Dispersive X-ray Fluorescence (WDXRF) Analysis Results}

Table 1 shows WDXRF analysis results of the samples. Elemental distribution in samples is found similar within the same group (Alloyed White Cast Iron (WCI) and Martensitic Stainless Steel (MSS)).

Table 1. Chemical compositions of Samples (wt $\%$ )

\begin{tabular}{|c|c|c|c|c|c|c|c|c|c|c|c|}
\hline $\begin{array}{l}\text { Weight Ratios of } \\
\text { Elements (wt } \% \text { ) }\end{array}$ & $\mathrm{Fe}$ & $\mathrm{Si}$ & S & $\mathrm{P}$ & $\mathrm{Mn}$ & $\mathrm{Ni}$ & $\mathrm{Cu}$ & $\mathrm{Ti}$ & V & Mo & $\mathrm{Cr}$ \\
\hline $\begin{array}{c}\text { WCI } \\
\text { (Sample I) }\end{array}$ & 91.8 & 1.55 & 0.030 & 0.016 & 0.343 & 0.23 & 0.098 & 0.05 & 0.016 & 0.16 & 5.56 \\
\hline $\begin{array}{c}\text { WCI } \\
\text { (Sample II) }\end{array}$ & 90.1 & 1.47 & 0.036 & 0.020 & 0.285 & 0.188 & 0.062 & - & - & 0.14 & 5.16 \\
\hline $\begin{array}{c}\text { WCI } \\
\text { (Sample III) }\end{array}$ & 91.9 & 1.48 & 0.026 & 0.015 & 0.296 & 0.24 & 0.081 & 0.04 & 0.017 & 0.16 & 5.57 \\
\hline $\begin{array}{c}\text { MSS } \\
\text { (Sample IV) }\end{array}$ & 75.6 & 0.740 & 0.082 & 0.017 & 0.770 & 0.714 & 0.086 & - & 0.077 & 0.601 & 20.9 \\
\hline $\begin{array}{c}\text { MSS } \\
\text { (Sample V) }\end{array}$ & 75.9 & 0.776 & - & 0.015 & 0.804 & 0.718 & 0.080 & - & 0.076 & 0.601 & 20.5 \\
\hline $\begin{array}{c}\text { MSS } \\
\text { (Sample VI) }\end{array}$ & 76.3 & 0.757 & 0.084 & 0.014 & 0.856 & 0.787 & 0.105 & - & 0.088 & 0.611 & 20.1 \\
\hline
\end{tabular}

\subsection{Microstructural Examinations}

Fig 3. shows the microstructure of (Alloyed White Cast Iron (WCI)) samples. These figures suggest that WCI microstructures consist of martensitic matrix structure with some amount carbides and retained austenite content (dark patches). These microstructures have also been reported before in the similar studies $[12,13]$. 


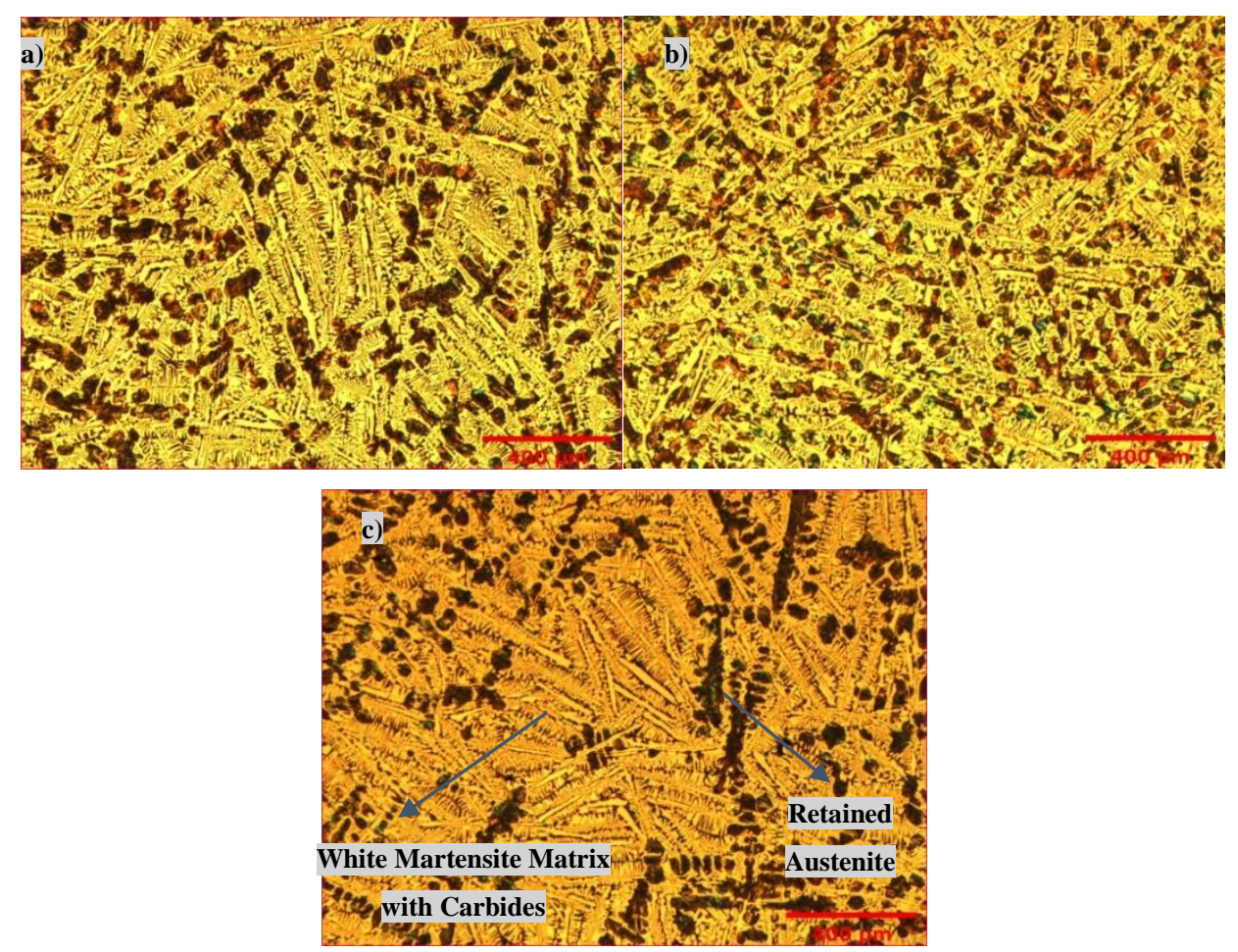

Figure 3. Optical Micrographs of WCI Samples a) Sample I b) Sample II c) Sample III

Unwanted phases such as intermetallic phases, carbides, and nitrides may exist in the steel if the casting process is not carefully managed. High levels of ferrite stabilizer elements, such as silicon, molybdenum, and chromium can enhance the formation of the sigma phases [14]. Fig 4. illustrates the microstructures of MSS samples. Microstructures of MSS samples have mainly two different phases. White carbide phases can be revealed by optical micrographs. These white carbides contains martensite structure and they are uniformly dispersed and their shapes are irregular.

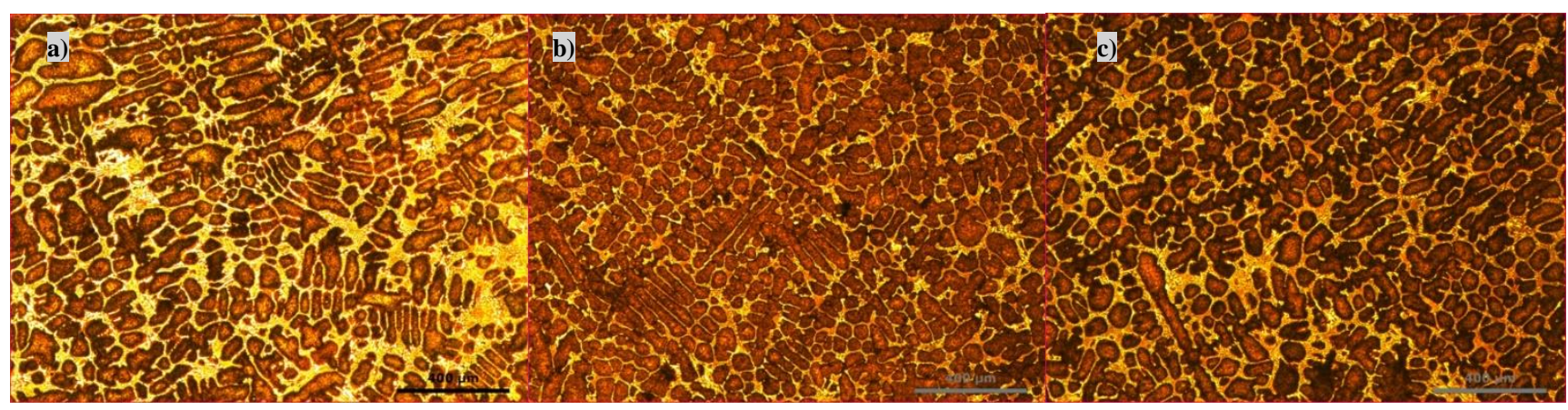

Figure 4. Optical Micrographs of MSS samples a) Sample IV b) Sample V c) Sample VI

Fig. 5. shows the detail structure view of these phases at higher magnification. There is a black austenite structure between the white carbides. In that structure, some micro-carbide precipitates can be also seen. 


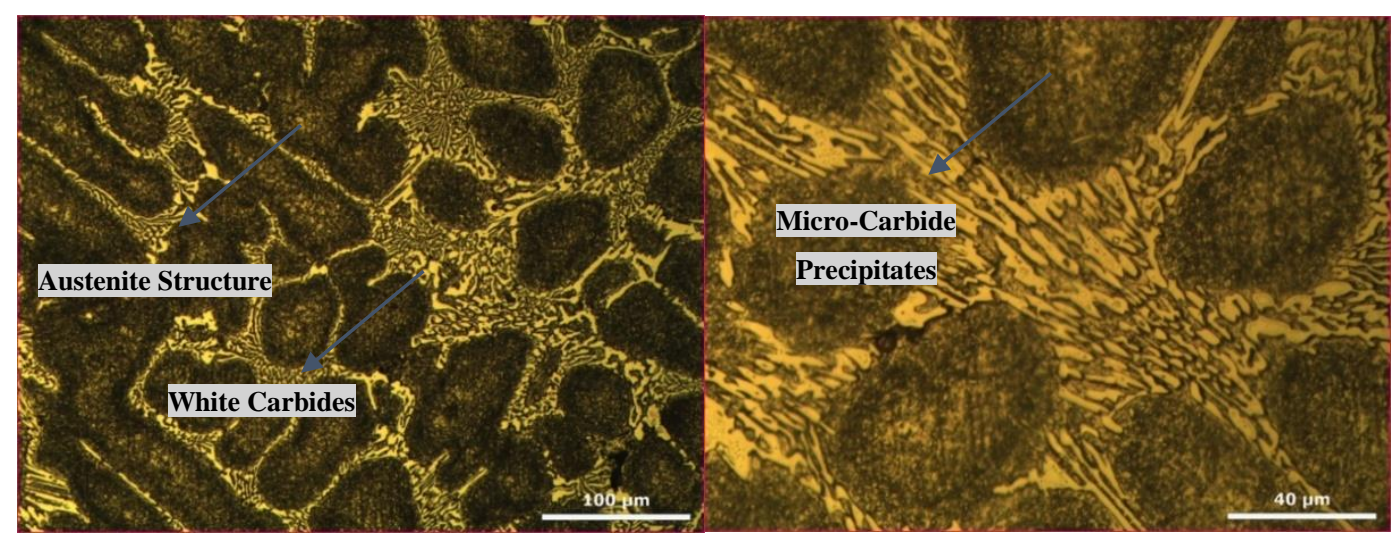

Figure 5. Closer view of phases of a MSS Sample

\subsection{Hardness Measurements}

Vickers hardness measurement results can be seen in Fig 6. The results show that MSS samples have more uniform hardness distribution and higher hardness values compared to WCI samples.

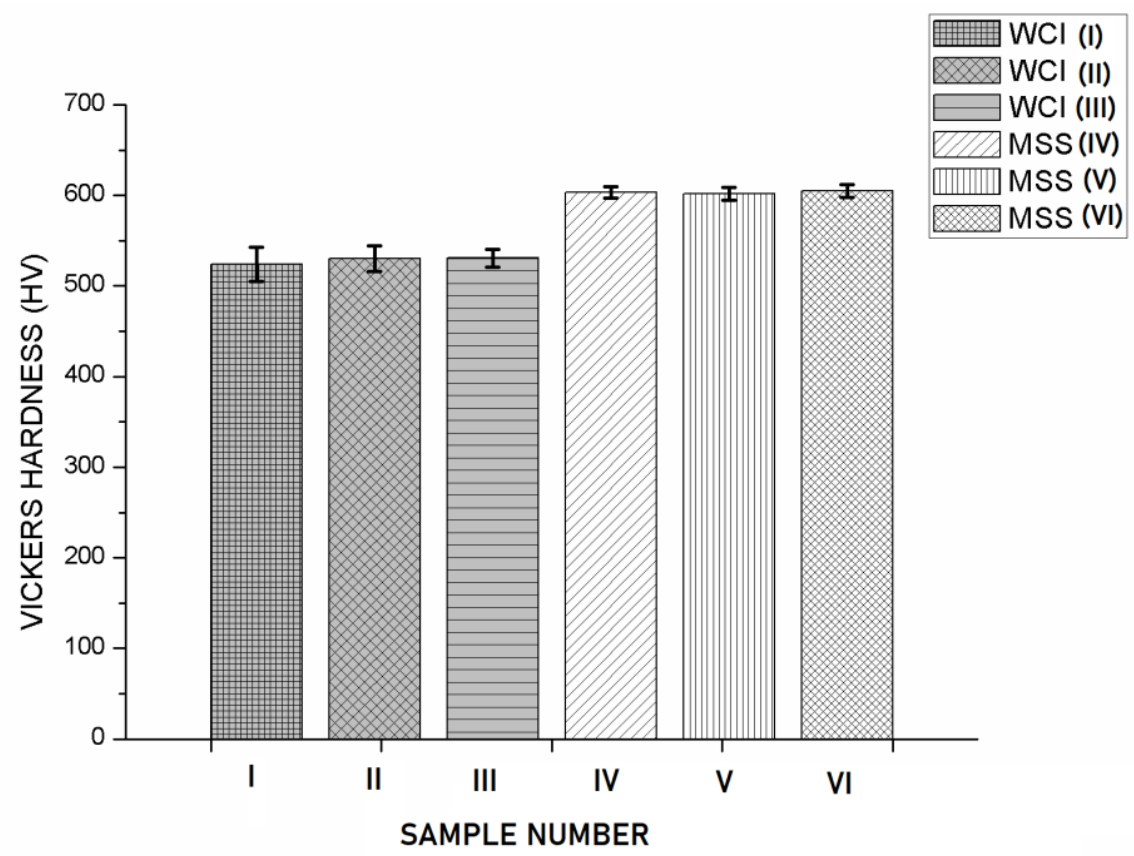

Figure 6. Vickers hardness measurement results of samples

\subsection{Potentiodynamic Polarization Measurement Results}

It is a known fact that $\mathrm{Cr}_{2} \mathrm{O}_{3}$ thin film protects the steel against corrosion if there is sufficient chromium content in the composition of the steel. The polarization curves of the MSS samples shows better corrosion resistance, which can be seen in Fig. 7. If the composition is deficient in chromium and it is rich in iron, corrosion resistance reduces, which enhances the probability of pitting corrosion $[15,16]$. Fig. 7. shows those pitting corrosion behaviour and $\mathrm{E}_{\text {pit }}$ values which are around $-0.68 \mathrm{~V}$. 


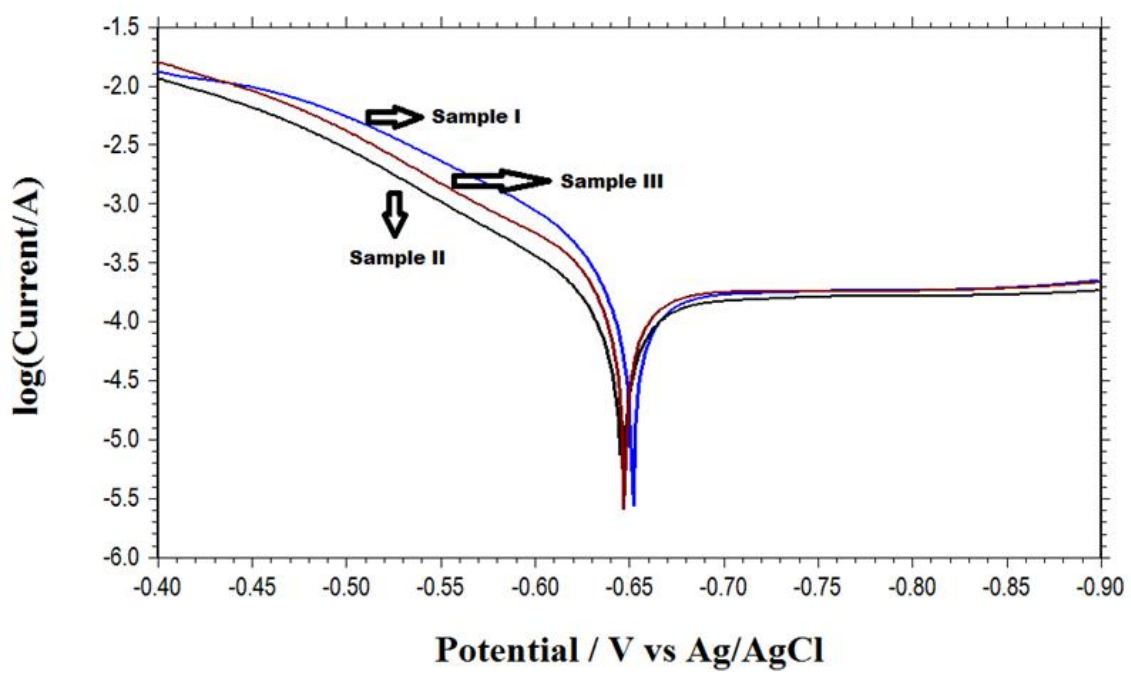

Figure 7. Polarization Curves of WCI Samples

Polarization curves of the WCI samples can be shown at Fig. 7 and polarization curves of the MSS samples can be shown at Fig. 8 .

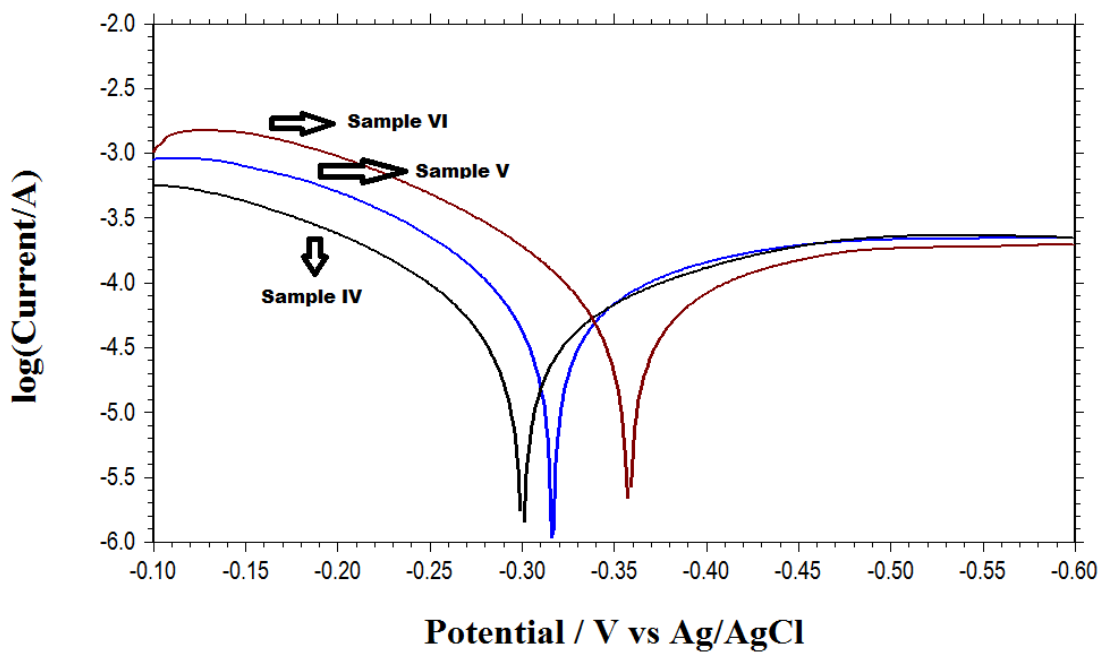

Figure 8. Polarization Curves of MSS Samples

Table 2 gives the $\mathrm{E}_{\text {corr }}, \mathrm{I}_{\text {corr }}$ and corrosion rate values of the samples. The results showed that the most noble corrosion potential $(-300 \mathrm{mV})$ is belong to MSS sample, where the corrosion potential of another MSS samples is (-317 $\mathrm{mV})$ and ($358 \mathrm{mV}$ ). The corrosion potentials of WCI samples are $-652 \mathrm{mV},-649 \mathrm{mV}$ and $-647 \mathrm{mV}$ respectively. Corrosion current densities of WCI samples increased considerably compared to the MSS samples, which indicates the lower corrosion resistance. Mean corrosion rates showed that WCI samples have vulnerability up to 6 times in comparison with MSS samples. 
Table 2. $\mathrm{I}_{\text {corr }}, \mathrm{E}_{\text {corr }}$ and corrosion rate values of the samples

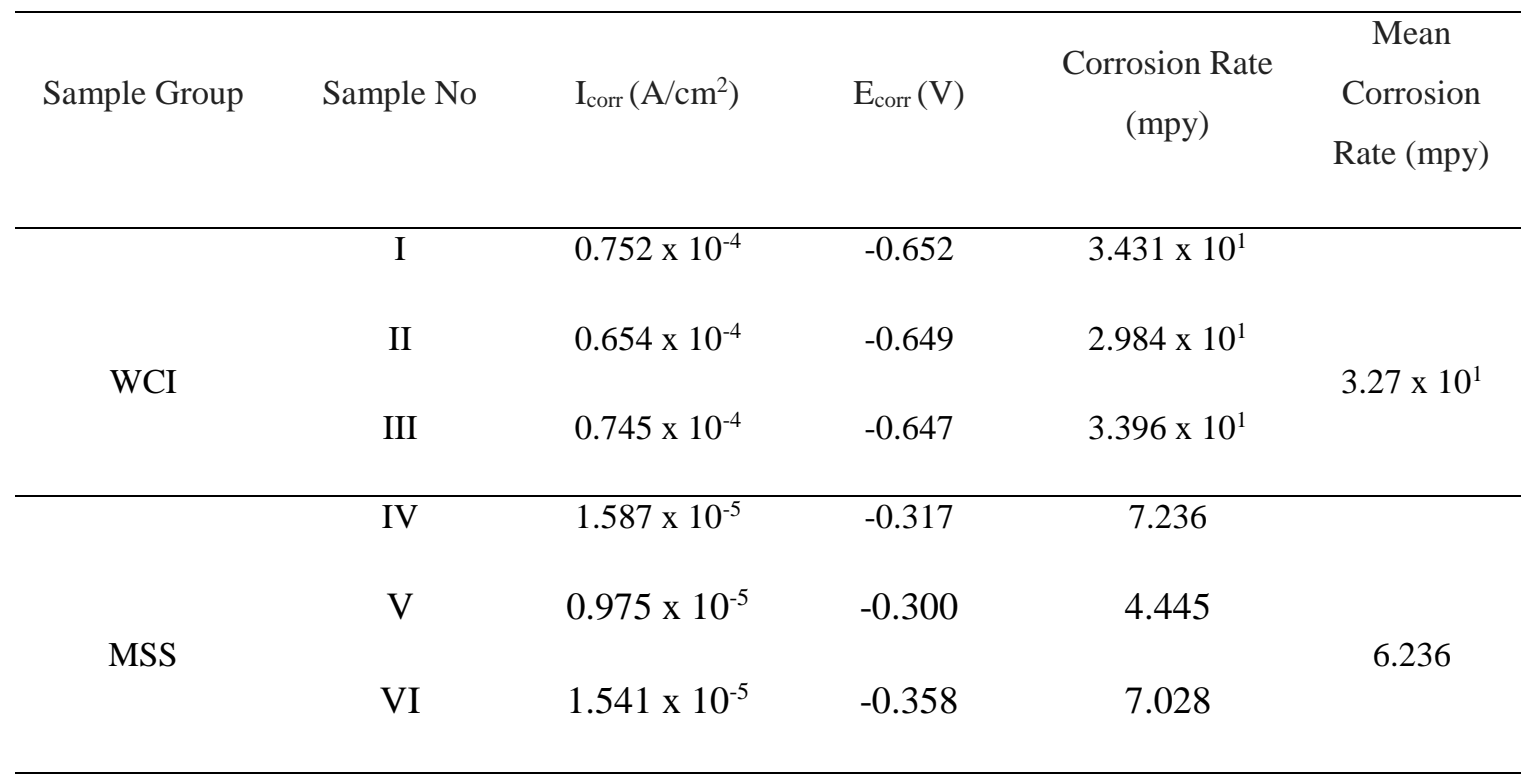

\section{Conclusion}

The current study aimed at conducting a series of tests to investigate and compare microstructure, mechanical strength and corrosion resistance of WCI and MSS samples produced by centrifugal casting method. The microstructural observations showed that WCI samples have martensitic and carbide matrix structure with some retained austenite grains while MSS samples have carbides and austenite grains. The hardness results showed that WCI samples have lower hardness values than MSS samples and have more non-homogenous hardness distribution. The WCI samples showed pitting formation and more sensitive behavior against corrosion. As expected, MSS samples had good corrosion resistance in $\% 3.5 \mathrm{NaCl}$ solution and corrosion rates were five times less than WCI samples.

\section{References}

[1] Fu, H., Xiao, Q., \& Xing, J. D. (2008). A study on the crack control of a high-speed steel roll fabricated by a centrifugal casting technique. Materials Science and Engineering: A, 474(1-2): 82-87.

[2] Stefanescu, D. M., Davis, J. R., \& Destefani, J. D. (1988). Metals Handbook, Vol. 15 -Casting. ASM International, 1988, 937.

[3] Davis, J. R. (Ed.). (1996). ASM specialty handbook: cast irons. ASM international. p. 171.

[4] CES EduPack Software (2013), Granta Design Limited, Cambridge, UK.

[5] Wadsworth, J., \& Lesuer, D. R. (2000). Ancient and modern laminated composites-from the Great Pyramid of Gizeh to Y2K. Materials Characterization, 45(4-5): 289-313.

[6] Strnadel, B., \& Haušild, P. (2008). Statistical scatter in the fracture toughness and Charpy impact energy of pearlitic steel. Materials Science and Engineering: A, 486(1-2): 208-214. 
[7] Zumelzu, E., Goyos, I., Cabezas, C., Opitz, O., \& Parada, A. (2002). Wear and corrosion behaviour of highchromium (14-30\% Cr) cast iron alloys. Journal of Materials Processing Technology, 128(1-3): 250-255.

[8] Singh, R. (2015). Applied welding engineering: processes, codes, and standards. Butterworth-Heinemann. p. 57-64.

[9] Marcuci, J. R. J., Souza, E. C. D., Camilo, C. C., Di Lorenzo, P. L., \& Rollo, J. M. D. D. A. (2014). Corrosion and microstructural characterization of martensitic stainless steels submitted to industrial thermal processes for use in surgical tools. Revista Brasileira de Engenharia Biomédica, 30(3): 257-264.

[10] Zumelzu, E., Goyos, I., Cabezas, C., Opitz, O., \& Parada, A. (2002). Wear and corrosion behaviour of highchromium (14-30\% Cr) cast iron alloys. Journal of Materials Processing Technology, 128(1-3): 250-255.

[11] Garrison Jr, W. M., \& Amuda, M. O. H. (2017). Stainless Steels: Martensitic. Reference Module in Materials Science and Materials Engineering

[12] Yousif I. F. \& Ataiwi A.H. (2018). Effects of heat treatment on erosion behavior and microstructure of high chromium white cast iron, Journal of Engineering and Applied Sciences, 13: 2376-2381

[13] Ataiwi, A. H. (2019). Study the Microstructure and Mechanical Properties of High Chromium White Cast Iron (HCWCI) under Different Martempering Quenching Mediums. Engineering and Technology Journal, 37(4part (A) Engineering), 112-119.

[14] Acton, Q. A. (2013). Iron Compounds-Advances in Research and Application: 2013 Edition: ScholarlyBrief. ScholarlyEditions. pp. 197-199.

[15] Loto, R. T., \& Loto, C. A. (2017). Potentiodynamic polarization behavior and pitting corrosion analysis of 2101 duplex and 301 austenitic stainless steel in sulfuric acid concentrations. Journal of Failure Analysis and Prevention, 17(4): 672-679.

[16] El-Aziz, K. A., Zohdy, K., Saber, D., \& Sallam, H. E. M. (2015). Wear and corrosion behavior of high-Cr white cast iron alloys in different corrosive media. Journal of Bio-and Tribo-Corrosion, 1(4): 25. 